Alma Mater Studiorum - Università di Bologna DEPARTMENT OF ECONOMICS

\title{
The spillover effects of gender quotas on dishonesty
}

Valeria Maggian

Natalia Montinari

Quaderni - Working Paper DSE $N^{\circ} 2007$

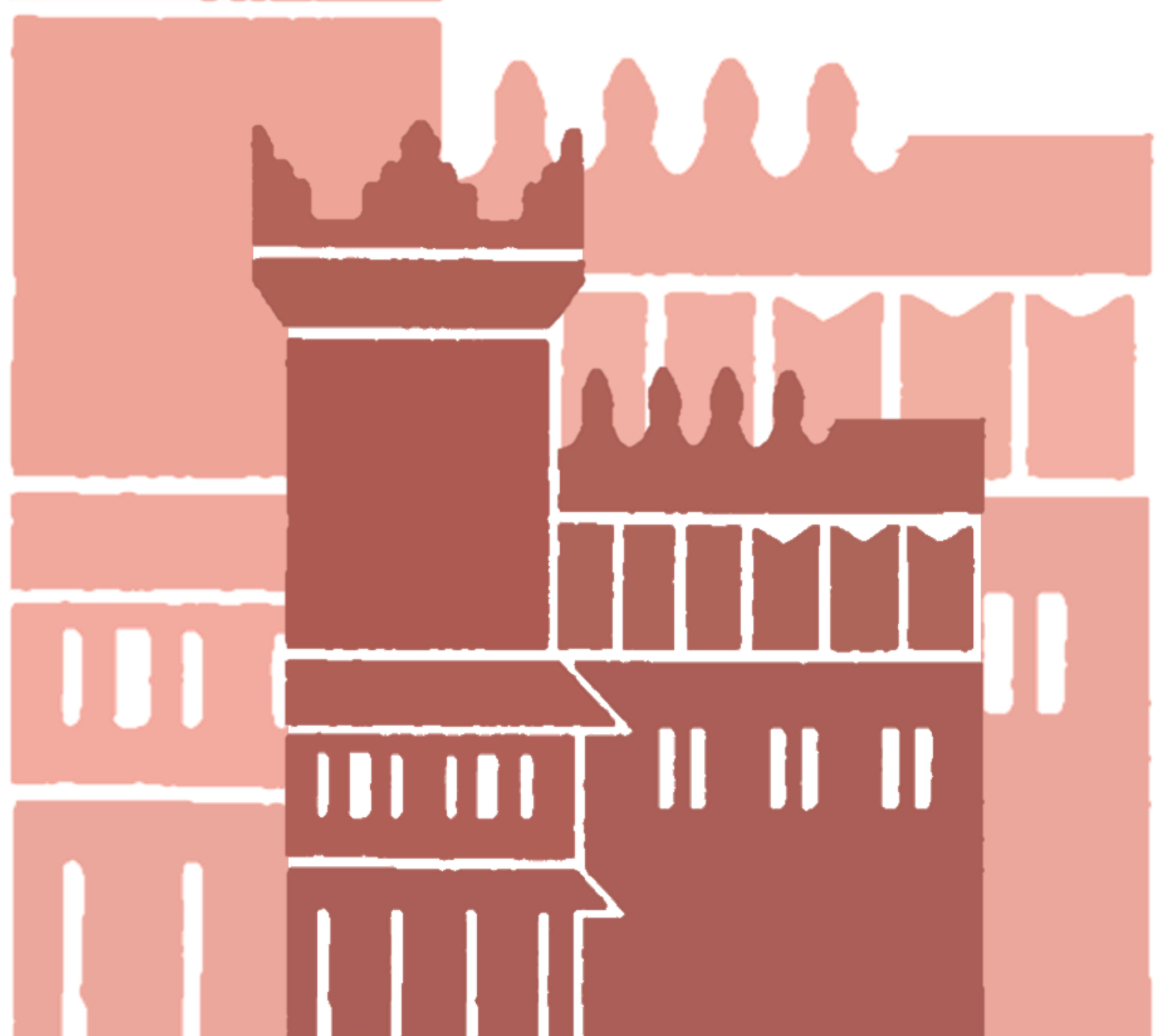




\title{
The spillover effects of gender quotas on dishonesty \\ Valeria Maggian $^{\dagger}$, Natalia Montinari ${ }^{\ddagger}$
}

\begin{abstract}
We experimentally test for spillover effects of gender quotas on subsequent unrelated, unethical behavior. We find that introducing quotas has no systematic effect on unethical behavior for both genders. High performing, competitive females are more likely to display unethical behavior than their male counterparts.
\end{abstract}

Keywords: Affirmative action, spillover effects, unethical behavior, competition, laboratory experiments.

JEL: D03, C91, J24

\footnotetext{
"We thank Loukas Balafoutas Antonio Nicolò, Fabio Galeotti, and Marie Claire Villeval for useful discussions and Claire Rimbaud, Alice Solda and Quentin Thévenet for their laboratory assistance. The authors gratefully acknowledge the financial support of the Jan Wallander and Tom Hedelius Foundation, Handelsbanken, Sweden, (Research Grant P2016-0126:)1 for funding the experiment and the French National Research Agency (ANR, FELIS Grant, ANR-14-CE28-0010-01) for support on the implementation of the research. Valeria Maggian's contribution was performed within the framework of the LABEX CORTEX (ANR-11-LABX-0042) of Universite de Lyon, within the program Investissements d'Avenir (ANR-11-IDEX-007) operated by the French National Research Agency (ANR). Natalia Montinari's contribution was performed while she was a researcher at the Department of Economics of the Lund University, Sweden. The usual disclaimer applies.

${ }^{+\dagger}$ Univ Lyon, CNRS, GATE L-SE UMR 5824, F-69130 Ecully, France.

$\ddagger$ Corresponding Author: Natalia Montinari, University of Bologna, Piazza Scaravilli 2, 40126, Bologna, Italy. E-mail: natalia.montinari2@unibo.it
} 


\section{Introduction}

A growing literature highlights the effectiveness of affirmative actions in closing the gender gap in competitive environments. While previous studies provide evidence that quotas positively affect women's participation without hurting efficiency (Balafoutas and Sutter, 2012; Villeval, 2012; Niederle et al., 2013), little is known about the effects of introducing a quota on subsequent behavior of both men and women.

Sutter and Balafoutas (2012) find that introducing quotas and other affirmative actions do not entail efficiency losses in a following coordination task. Similarly, no harmful spillover effects of quotas are found on later performance within teams (Kölle, 2016). In an artefactual field experiment in the context of castes, Banerjee et al. (2016) conclude that being exposed to an affirmative action policy has no impact on subsequent unethical behavior and spite against subjects from the benefited group.

In the presence of quotas, the decision to hire or promote individuals is based on observable characteristics (i.e. gender), different than merit. Working in such an environment may be perceived as unfair (Harrison et al. 2006) and lead to a higher moral flexibility, inducing individuals to engage in self-serving dishonesty (Houser et al. 2012). For men, the introduction of a quota may justify dishonest behavior as a corrective mechanism against reverse discrimination. Women may be more likely to cheat in the absence of quotas, possibly because feeling disadvantaged with respect to men.

We investigate the possible spillover effects of gender quotas on subsequent, unrelated, unethical behavior.

\section{The experiment}

Our experiment has two parts; subjects were informed about Part 2 only after the completion of Part 1.

Part 1 is divided in 5 stages. Subjects were randomly assigned into groups composed by six men and six women. The experimental task in each stage was to add as many sets of three three-digit numbers and two decimal numbers as possible within 4 minutes (similar to Niederle and Vesterlund, 2013).

In stage 1 (piece rate), subjects receive $€ 0.50$ for each correct calculation. In stage 2 (compulsory tournament), group members compete against each other. The four members who solve the most calculations are paid $€ 1.50$ per correct answer. The other eight group members receive nothing. In stage 3 (choice1) subjects choose whether they want to be paid under a piece rate or a tournament scheme (receiving a payoff of $€ 1.50$ when being among the four winners, nothing otherwise). In stage 4 (choice2), only those subjects who did choose the competition in choice1, can decide whether they want to be paid under a piece rate or a tournament scheme (receiving a payoff of 
$€ 3$ per calculation when being among the two winners, nothing otherwise). ${ }^{1}$ In both stages 3 and 4 , if the tournament is chosen, the subject's performance in the task is compared to the other group members' performance in stage 2. Stages 3 and 4 replicate a career ladder: when choosing the tournament in stage 4 , this payment scheme is applied conditionally on being among the winners of stage 3 competition.

To examine the effects of quotas, we vary the competition rules across two treatments.

In the NoQuota Treatment (NQT), the winners in stage 3 and stage 4 are, respectively, the four and two group members with the largest numbers of correct calculations, regardless of gender.

In the Quota Treatment (QT) we introduce a quota both in stage 3 and stage 4. In stage 3 at least two women have to be among the four winners of the tournament, irrespective of the ordinal ranking of group members' performances. Therefore, the two best-performing women are always winners in stage 3 . Similarly, in stage 4 the best best-performing woman is always a winner. After the decision in stage 4 we elicit participants' beliefs about relative ranking in stage 2 .

In stage 5 we elicit risk preferences as in Crosetto and Filippin, (2013). In each stage no information about previous payoffs was given to subjects until the end of part 2.

In Part 2 we measure the possible spillovers of gender quotas on subsequent dishonest behavior using a variation of the die under-the-cup task (Shalvi et al., 2011). In our experiment, reporting an odd number results in getting $€ 4$ while reporting an even number results in getting $€ 1$.

The experiment was conducted using z-Tree (Fischbacher, 2007), subjects were recruited using HROOT (Bock et al. 2014). From September to December 2016, 192 subjects participated, divided in four sessions of 24 subjects per treatment. Subjects received a show-up fee of $€ 5$ plus their earnings from one randomly selected stage between 1 and 4 , their earnings from stage 5 and from the die under-the-cup task.

\section{Results}

Figure 1 displays the proportion of men and women reporting an odd number in the die-under-the-cup task under the NoQuota and Quota treatment. Overall, both men and women reported a significantly higher number of odd numbers than $50 \%(p=0.00)$. Women are slightly more likely to report an odd number than men, but differences between genders are not significant both within treatment $\left(\chi^{2}(1)=1.64, p=0.20\right)$ and across treatments (NQT: $\chi^{2}(1)=0.00, p=1.00$; QT: $\chi^{2}(1)=0.06, p=0.81$ ). This evidence suggests that introducing quotas has no systematic effect on subsequent cheating behavior on both genders.

\footnotetext{
${ }^{1}$ We use the strategy method for the decision to compete in stage 4. See the Experimental Instructions in the Supplementary Material.
} 


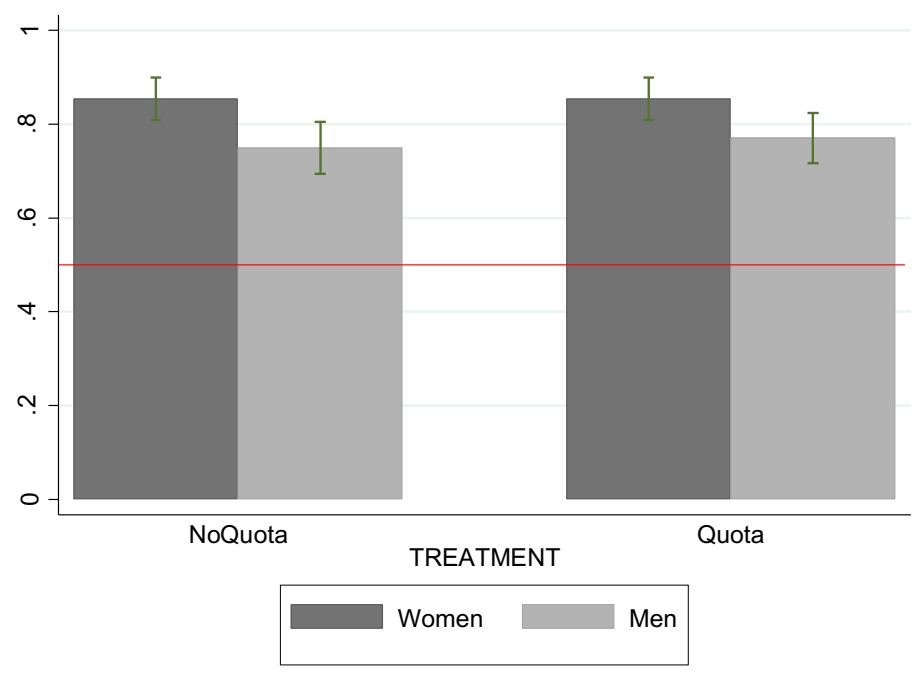

Figure 1: Proportion of men and women reporting an odd number in the die under-the-cup task, by treatment. Red line indicates $\mathbf{5 0} \%$.

We further investigate if performance affects the individual's decision to report an odd number. Participants with high performance might be less reluctant to lie to maximize their payoffs by doing so, because of a feeling of entitlement (Schurr and Ritov, 2016). Participants with low performance might be willing to lie to recover for their losses.

We identify as high performers those participants ranked in the top 4 positions in the compulsory tournament (stage 2 ). We do not find significant difference on the reporting decision of high performers compared to other (lower ranked) subjects within treatments $\left(\mathrm{NQT}: \chi^{2}(1)=0.95, \mathrm{p}=0.33\right.$; QT: $\left.\chi^{2}(1)=0.22, \mathrm{p}=0.64\right)$. Similarly, we observe no treatment effect in high $\left(\chi^{2}(1)=0.13, p=0.72\right)$ or lower ranked individuals $\left(\chi^{2}(1)=0.01, p=0.90\right)$. However, when considering both treatments together, high performers females were significantly more likely to report an odd number than their male counterparts $\left(\chi^{2}(1)=3.40, \mathrm{p}=0.07, \mathrm{~N}=79\right)$. Gender differences are not significant for the lower ranked performers $\left(\chi^{2}(1)=0.21, p=0.64, N=113\right)$. 
a. Competition in stage 3

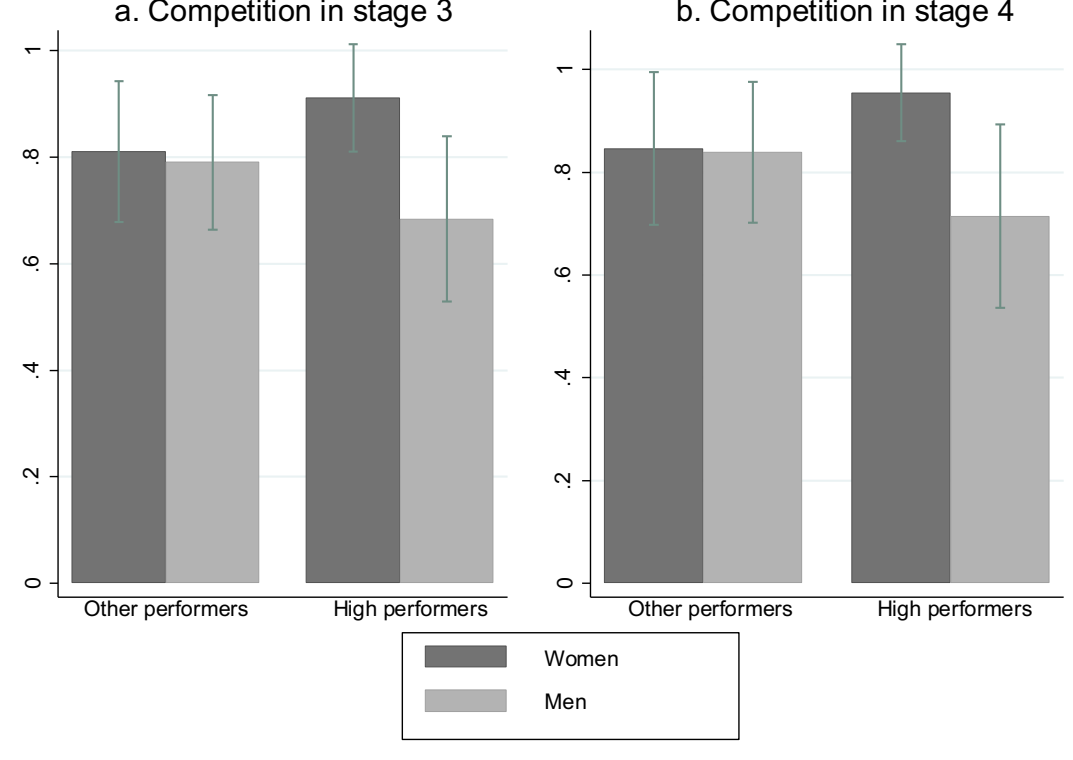

Figure 2: Proportion of men and women reporting an odd number in the die under-the-cup task depending on their stage 2 performance and on their competitive choice in stage 3 and 4 . Error bars indicate $95 \%$ confidence intervals.

Next, we investigate the effect of the individual's willingness to compete on unethical behavior. While previous experiments focused on the effect of tournaments on honesty when compensation is tied to relative performance, differently than us, they cannot disentangle among the effect of competition per se and the effect of strategic choice of competition on dishonest behavior (Conrads et al., 2014; Dato and Nieken, 2015; Schurr and Ritov, 2016). Figure 2 displays the proportion of men and women reporting an odd number in the die under-the-cup task depending on whether they chose competition in stage 3 (panel a, N=152) and in stage 4 (panel b, N=107). Gender differences remain significant for high performers: females who chose competition are more likely to report an odd number than their males' counterpart (Fisher's exact tests, stage 3: $p=0.02, N=72$; stage 4: $p=0.06, N=50$ ). Gender differences are not significant for the other participants (stage 3: $\chi^{2}: p=0.82$; stage 4, Fisher's exact test: $p=1.00$ ). The interaction between female and performance in stage 2 is positive and marginally significant (see models (4)- (5), Table 1, showing the extent to which the difference in the probability to report an odd number between males and females changes with respect to performance. ${ }^{1}$

These results suggest that high performing women, when experiencing and choosing a competitive environment, are more prone than men to lie to increase their payoff, independently on the presence of gender quotas.

\footnotetext{
${ }^{1}$ If we include beliefs about own ranking in stage 2 in model 5 , its coefficient is not significant and other results are unchanged. The same is observed when including the field of study.
} 
Table 1. Determinants of unethical behavior.

Dependent Variable

1 if an odd number is reported, 0 otherwise

\begin{tabular}{|c|c|c|c|c|c|}
\hline Independent variables & (1) & (2) & (3) & (4) & (5) \\
\hline Quota & 0.010 & 0.011 & -0.079 & -0.068 & -0.073 \\
\hline 1 if Quota, 0 otherwise & $(0.057)$ & $(0.057)$ & $(0.067)$ & $(0.067)$ & $(0.067)$ \\
\hline Female & 0.094 & 0.089 & $0.135^{* *}$ & -0.176 & -0.146 \\
\hline 1 if Woman, 0 otherwise & $(0.056)$ & $(0.057)$ & $(0.064)$ & $(0.185)$ & $(0.180)$ \\
\hline $\begin{array}{l}\text { Performance in stage } 2 \\
\text { (compulsory tournament) }\end{array}$ & & $\begin{array}{l}-0.009 \\
(0.016)\end{array}$ & $\begin{array}{l}-0.008 \\
(0.019)\end{array}$ & $\begin{array}{l}-0.032 \\
(0.024)\end{array}$ & $\begin{array}{l}-0.030 \\
(0.022)\end{array}$ \\
\hline $\begin{array}{l}\text { Competition in stages } 3 \text { and } 4 \\
1 \text { if competition is chosen both in } \\
\text { stage } 3 \text { and } 4,0 \text { if competition is } \\
\text { chosen only at stage } 3\end{array}$ & & & $\begin{array}{l}0.162^{* *} \\
(0.083)\end{array}$ & $\begin{array}{l}0.174^{* *} \\
(0.084)\end{array}$ & $\begin{array}{l}0.152^{* *} \\
(0.082)\end{array}$ \\
\hline $\begin{array}{l}\text { Performance in compulsory } \\
\text { tournament x Female }\end{array}$ & & & & $\begin{array}{l}0.076^{*} \\
(0.041)\end{array}$ & $\begin{array}{l}0.072^{*} \\
(0.040)\end{array}$ \\
\hline $\begin{array}{l}\text { Risk aversion } \\
\text { Continuous variable between } 1 \\
\text { (risk averse) and } 100 \text { (risk lover) }\end{array}$ & & & & & $\begin{array}{l}-0.005^{* *} \\
(0.002)\end{array}$ \\
\hline Observations & 192 & 192 & 152 & 152 & 152 \\
\hline Pseudo $R^{2}$ & 0.0147 & 0.0166 & 0.0517 & 0.0735 & 0.1082 \\
\hline LR chi2 & 2.77 & 3.13 & 7.95 & 11.30 & 16.63 \\
\hline Prob > chi2 & 0.2508 & 0.3724 & 0.0933 & 0.0458 & 0.0107 \\
\hline
\end{tabular}

Notes: The table reports marginal effects of the respective independent variables on the probability of reporting an odd number. Standard errors in parentheses. Significance levels: *: $p$ $<0.10 ;{ }^{* *}: p<0.05 ;{ }^{* * *}: p<0.01$.

\section{Conclusion}

We examine the spillover effects of gender quotas on unethical behavior: quotas have no effect on men and women's reporting behavior. However, we find that high performing competitive females are more likely to engage in dishonest reporting in a die-under-cup task with respect to their male counterparts. The mechanism explaining this evidence might be a feeling of redemption associated with being a high performing woman in a male-stereotyped environment. Further research is needed to test the link between tournament-like incentives, the task used, and subsequent unethical behavior.

ONLINE APPENDIX: click here 


\section{References}

Balafoutas, L., Sutter, M., 2012. Affirmative action policies promote women and do not harm efficiency in the laboratory. Science 335 (6068), 579-582.

Banerjee, R., Datta Gupta, N., Villeval, M. C., 2016. The Spillover Effects of Affirmative Action on Competitiveness and Unethical Behavior. Working paper GATE 2016-34.

Bock, O., Baetge, I., Nicklisch, A., 2014. hroot: Hamburg registration and organization online tool. European Economic Review, 71: 117-120.

Conrads, J., Irlenbusch, B., Rilke, R. M., Schielke, A., Walkowitz, G., 2014. Honesty in tournaments. Economics Letters 123, 90-93.

Crosetto, P., Filippin, A., 2013. The "bomb" risk elicitation task. Journal of Risk and Uncertainty 47(1), 31-65.

Dato, S., Nieken, P., 2015. Compensation and Honesty: Gender Differences in Lying. Karlsruhe Institute of Technology Discussion Paper No. 15-20.

Fischbacher, U., 2007. z-tree: Zurich toolbox for ready-made economic experiments. Experimental economics 10(2), 171-178.

Harrison, D. A., Kravitz, D. A., Mayer, D. M., Leslie, L. M., \& Lev-Arey, D. 2006. Understanding attitudes toward affirmative action programs in employment: Summary and meta-analysis of 35 years of research. Journal of Applied Psychology, 91: 10131036.

Houser, D., Vetter, S., \& Winter, J. (2012). Fairness and cheating. European Economic Review, 56(8), 1645-1655.

Kölle, F., 2016. Affirmative Action and Team Performance. Discussion Papers 201607, The CEDEX, School of Economics, University of Nottingham.

Niederle, M., Segal, C., Vesterlund, L., 2013. How costly is diversity? Affirmative action in light of gender differences in competitiveness. Management Science 59, 1-16.

Shalvi, S., Dana, J., Handgraaf, M.J.J., De Dreu, C.K.W. 2011. Justified ethicality: Observing desired counterfactuals modifies ethical perceptions and behavior. Organizational Behavior and Human Decision Processes, 115 (2): 181-190.

Schurr, A., Ritov, I., 2016. Winning a competition predicts dishonest behavior. PNAS 113 (7), 1754-1759.

Villeval, M. C., 2012. Ready, steady, compete. Science 335 (6068), 544-545. 


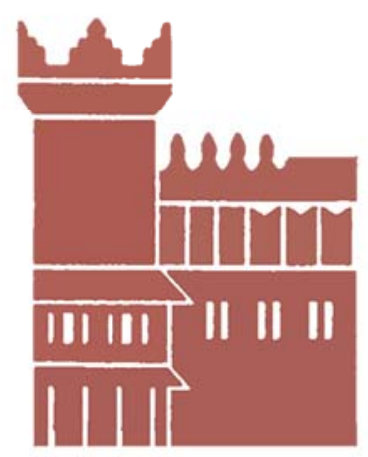

Alma Mater Studiorum - Università di Bologna DEPARTMENT OF ECONOMICS

Strada Maggiore 45

40125 Bologna - Italy

Tel. +39051 2092604

Fax +390512092664

http://www.dse.unibo.it 